\title{
Es aceptable no prescribir antibióticos en niños mayores con infección respiratoria baja no complicada
}

\section{Objetivo}

Estimar la efectividad de tres estrategias prescriptivas y de la provisión de información mediante folletos en infecciones respiratorias agudas bajas.

\section{Diseño}

Ensayo clínico controlado y aleatorizado factorial* .

Lugar

Inglaterra.

\section{Pacientes}

Se incluyeron 807 niños de tres años o más con tos como principal síntoma y al menos un criterio de infección respiratoria baja (taquipnea , tiraje o tos ${ }^{1}$ ) pero sin criterios de complicación (inmunodepresión, hipoxemia, inestabilidad hemodinámica)

\section{Intervención}

Se asignaron tres estrategias de prescripción de antibióticos: inmediatos $(n=262)$, no oferta $(n=273)$ y "demorados" o disponibilidad de usarlos si los síntomas no resolvían en 14 días $(n=272)$. Todos los pacientes recibieron información verbal y aproximadamente la mitad de cada grupo recibió información mediante folletos sobre la historia natural de la enfermedad, preocupaciones previsibles de los pacientes y advertencias de cuándo buscar ayuda adicional.

\section{Medición de Resultados Principales}

El punto final primario fue duración y severidad de los síntomas. Los pacientes llevaban una agenda diaria donde reportaban fiebre, antipiréticos utilizados y síntomas. Secundariamente se midieron satisfacción y creencias en la necesidad de uso de antibióticos, as como tasa de reconsultas. Las agendas fueron revisadas por un autor "ciego" al grupo asignado. Se analizaron los datos por intención de tratar.

\section{Resultados Principales}

No se observó efecto alguno del folleto en los resultados primarios.
Comparadas con la no oferta de antibióticos, las otras estrategias no alteraron la duración de la tos ni otros puntos finales primarios. Ver tabla 1.

Tabla 1. Puntos finales primarios y principales diferencias entre intervenciones

\begin{tabular}{|c|c|c|c|c|c|c|c|c|}
\hline & $\begin{array}{c}\text { No folleto } \\
\text { (Control) } \\
\text { Promedio } \\
\text { (LS) }\end{array}$ & $\begin{array}{l}\text { Oifierentia } \\
\text { debitio a } \\
\text { folletos } \\
\text { (LE } 95 \% \text { ) }\end{array}$ & $\begin{array}{l}\text { Valor } \\
\text { de P }\end{array}$ & \begin{tabular}{|c|} 
No ATB \\
(Gountral) \\
Promeditio \\
(DS)
\end{tabular} & $\begin{array}{r}\text { Difer } \\
\text { debida } \\
\text { denn } \\
\text { (CC) }\end{array}$ & $\begin{array}{l}\text { Valor } \\
\text { de P }\end{array}$ & $\begin{array}{l}\text { cia } \\
\text { ATB } \\
\text { os } \\
\text { ol }\end{array}$ & $\begin{array}{l}\text { V Valor } \\
\text { de } P\end{array}$ \\
\hline zicón c & \begin{tabular}{|l|l}
$11,6(5,8)$ \\
\end{tabular} & $\begin{array}{c}0,26 \\
\mathrm{a} 1,1,06\end{array}$ & 68 & $11,4(5,8)$ & $\begin{array}{r}0,75 \\
\mathrm{a} 1 \\
\end{array}$ & 0,19 & - & \\
\hline $\begin{array}{l}\text { ación de la tos hasta } \\
\text { ninución moderadad(das) }\end{array}$ & $5,8(4,1)$ & $\begin{array}{c}0,20(-1,60 \\
\text { a } 2,00) \\
\end{array}$ & 0,83 & $7(4,0)$ & $\begin{array}{c}0,13(-1,70 \\
\text { a } 2,00)\end{array}$ & 0,89 & $\begin{array}{r}0,52(-1,30 \\
\text { a 2,40) } \\
\end{array}$ & \\
\hline $\begin{array}{l}\text { ridad a } 2-4 \text { das de la } \\
\text { utta inicial (escala } 0-6 \text { ) }\end{array}$ & 1) & $\begin{array}{c}-0,03(0,20 \\
a 0,15) \\
\end{array}$ & 0,77 & $(1,2)$ & $\begin{array}{c}0,066(-0,15 \\
a 0,27) \\
\end{array}$ & \begin{tabular}{|l|}
0,56 \\
\end{tabular} & $\begin{array}{r}-0,10(-0,31 \\
\mathrm{a} 0,11) \\
\end{array}$ & 0,11 \\
\hline
\end{tabular}

Comparado con el grupo de antibióticos inmediatos, menos pacientes en el grupo demorados y en el control usaron antibióticos $(96 \%, 20 \%$ y $16 \%$ respectivamente; $p<0,01)$, la mayoría de los pacientes se sintió "muy satisfecho" con el tratamiento en todos los grupos $(86 \%, 77 \%$ y $72 \%$ respectivamente; $p=0,05)$, y más pacientes en el grupo antibióticos inmediatos creyeron en la efectividad de los mismos $(75 \%, 40 \%$ y $47 \%$ respectivamente; $p=$ $0,01)$. Hubo disminución de reconsultas dentro del mes con el uso de antibióticos (promedio de atención en grupo no antibióticos 0,19 ; demorados 0,12 ; inmediatos, 0,$11 ; p=0,04$ ) e incremento con el uso del folleto (promedio de atenciones sin folleto, 0,$11 ; y$ con folleto, 0,$17 ; p=0,02$ ).

\section{Conclusiones}

En pacientes con infección respiratoria aguda baja no complicada la demora o no prescripción de antibióticos parece una estrategia aceptable, ya que la diferencia en la duración y severidad de los síntomas en relación al grupo que recibió antibióticos inmediatos es mínima.

Fuente de Financiamiento: Medical Research Council.

\section{Comentario}

Las infecciones agudas del tracto respiratorio inferior comprenden una serie de enfermedades que tienen en común el causar dificultad respiratoria en los niños ${ }^{2}$. Constituyen un porcentaje importante de las consultas y motivo de prescripción de antibióticos en atención primaria. Hay consenso en la necesidad de disminuir esta prescripción, sobre todo en los casos no complicados, en los cuales la principal causa son los virus respiratorios, así como se ha logrado en la infecciones del tracto respiratorio superior.

En este estudio la oferta inmediata mostró una diferencia clínicamente poco relevante en la duración y severidad de los síntomas, reduciendo los mismos en un día en una enfermedad cuya historia natural es de tres semanas. Todas las estrategias fueron bien aceptadas por los pacientes, inclusive la no prescripción, hecho importante si tenemos en cuenta que una buena parte de las indicaciones de antibióticos se relacionan con la demanda de los pacientes. El estudio sugiere que el uso de antibióticos podría disminuir la tasa de reconsultas y el uso de folletos aumentarlas, esto último probablemente refleje las advertencias dentro del mismo de volver a consultar ante ciertas circunstancias (fiebre o dificultad respiratoria). De todas maneras es imprescindible la adecuada información y pautas de alarma a los padres, ya que estas infecciones constituyen una importante causa de mortalidad en la infancia en América Latina. Es importante destacar que los pacientes incluidos tenían por lo menos 3 años, ya que en los menores de esa edad estas infecciones revisten una mayor gravedad y características diferentes a las evaluadas en este estudio.

\section{Conclusiones del comentador}

Las diferencias entre las tres estrategias fueron mínimas, sugiriendo que la demora o no prescripción de antibióticos en niños mayores no complicados es aceptable y puede ayudar a limitar el círculo vicioso de la medicalización cuando se prescriben antibióticos en una enfermedad autolimitada.

Ricardo Sarandria [ Unidad de Medicina Familiar y Preventiva. Hospital Italiano de Buenos Aires. ]

Sarandria R.Es aceptable no prescribir antibióticos en niños mayores con infección respiratoria baja no complicada. Evid. Actual. Práct. Ambul. 2005;8:168. Comentado de.Little P et al. Information Leaflet and Antibiotic Prescribing Strategies for Acute Lower Respiratory Tract Infection. JAMA,june 22/29, 2005-Vol 293,No. 24; 3029:3035. PMID: 15972565

Referencias

1. Organización Mundial de la Salud. Normas de Infecciones Respiratorias Agudas en el niño menor de cinco años para el Primer Nivel de Atención. $4^{a}$ ed. Montevideo: Ministerio de Salud Pública, 1997.

2. Behrman R. et al. Nelson Textbook of Pediatrics.16th Edition 